\title{
Observations of Equatorial Kelvin Wave Modes in FORMOSAT-3/COSMIC GPS RO Temperature Profiles
}

\author{
Potula Sree Brahmanandam ${ }^{1,2, *}$, Yen-Hsyang $\mathrm{Chu}^{2}$, and Jimmy Liu ${ }^{2}$ \\ ${ }^{1}$ Department of ECE, KL University, Vaddeswaram, India \\ ${ }^{2}$ Institute of Space Science, National Central University, Jhongli, Taiwan, ROC
}

Received 25 August 2009, accepted 6 January 2010

\begin{abstract}
In this study, we analyze FORMOSAT-3/COSMIC (F3/C) GPS radio occultation (RO) derived temperature components for the period September 2006 to February 2008. Results show the presence of slow Kelvin waves (wave period > 10 days) with higher zonal wavenumbers (either one or two) in the upper troposphere and lower stratosphere (UTLS). The vertical wavelengths of these waves are found to be in the range of $5-12 \mathrm{~km}$. The predominant Kelvin waves observed in the temperature fluctuations are in the altitude range between 15 and $28 \mathrm{~km}$ and centered on the tropical tropopause. The downward phase progression of these waves suggests that the derived waves are propagating upward, with the source region located at lower altitudes possibly due to tropical convective heating. The zonal winds retrieved using radiosonde observations over Singapore $\left(1^{\circ} \mathrm{N}, 104^{\circ} \mathrm{E}\right)$ during this period show a periodicity of $\sim 24-26$ months in the stratosphere, and quasi-biennial oscillation (QBO) characteristics with eastward zonal winds from March 2006 to May 2007 and westward winds from June 2007 to July 2008 respectively. Our results further show that the Kelvin wave characteristics are enhanced during the westward phase of QBO and diminish during the eastward phase, in line with the previous reported results. Furthermore, an examination of outgoing longwave radiation (OLR) data shows that deep convection activity is developed episodically over the Indonesian archipelago during the observation period, thereby indicating that the Kelvin wave events observed in temperature fluctuations are either driven by convective activity (convectively coupled waves) or by a broad spectrum of convective variability (free waves) over the Indonesian region.
\end{abstract}

Key words: Radio occultation, QBO, Tropical convection

Citation: Brahmanandam, P. S., Y. H. Chu, and J. Liu, 2010: Observations of equatorial Kelvin wave modes in FORMOSAT-3/COSMIC GPS RO temperature profiles. Terr. Atmos. Ocean. Sci., 21, 829-840, doi: 10.3319/TAO.2010.01.06.01(A)

\section{INTRODUCTION}

Owing to large radiation inputs from the sun, the equatorial region acts as a source of atmospheric waves. Among the various waves, the planetary scale eastward propagating atmospheric waves with periods of $\sim 10-20$ days (slow), zonal wavenumbers 1 - 2 and phase speeds of $\sim 20-30 \mathrm{~m} \mathrm{~s}^{-1}$, known as Kelvin waves (Wallace and Kousky 1968) are thought to be produced by convective heating processes in the tropical troposphere (Holton 1972; Salby and Garcia 1987). Kelvin waves observed in the stratosphere are dominated by 'free' wave modes excited primarily by deep convection in the troposphere and not linked with the space-time

\footnotetext{
* Corresponding author

E-mail: anandp@jupiter.ss.ncu.edu.tw
}

patterns of the convective forcing (Randel and Wu 2005). Both convectively-coupled and free Kelvin waves can significantly influence the tropopause structure (Tsuda et al. 1994; Randel and Wu 2005; Ratnam et al. 2006) and thereby plays an important role in the stratosphere- troposphere exchange of ozone (Fujiwara et al. 1998), dehydrating air entering the lower stratosphere from the upper troposphere (Fujiwara et al. 2001), and occurrence of convective turbulence near the tropopause (Fujiwara et al. 2003). In addition, large-scale Kelvin and Rossby-gravity waves are thought to play an important role in driving the eastward phase of the quasi-biennial oscillation (QBO; Angell and Korshover 1964; Holton and Lindzen 1972) of the zonal winds of the equatorial stratosphere. Observational and numerical modeling studies suggest that the momentum fluxes of Kelvin 
and Rossby gravity waves are too meager (by factors of 2 - 4) to drive the $\mathrm{QBO}$ and that gravity waves probably play an important role (Hitchman and Leovy 1988; Alexander and Holton 1997; Dunkerton 1997; Canziani and Holton 1998; Baldwin et al. 2001). Recent studies (Tindall et al. 2006a, b; Alexander et al. 2008; Ern et al. 2008) have speculated that higher wavenumber ( $\mathrm{s} 44-7$ ) eastward and westward propagating equatorially trapped waves along with gravity waves contribute significantly to the total momentum flux transfer, which in turn plays a key role in the dynamics of the QBO.

Kelvin waves are characterized by using temperature and winds measured by radiosondes (for example, Wallace and Kousky 1968; Tsuda et al. 1994; Holton et al. 2001). Radiosonde observations though have the advantage of high vertical resolution, but they lack global coverage particularly over oceanic regions. In order to study the global behaviour and horizontal propagation characteristics of these waves, satellite-based measurements are more useful because they offer global coverage (Hirota 1979). The limb viewing satellite Nimbus-7 Limb Infrared Monitor of the Stratosphere (LIMS, vertical resolution $\sim 5 \mathrm{~km}$ ), Microwave Limb Sounder (MLS, vertical resolution $\sim 2.7 \mathrm{~km}$ ), Cryogenic Limb Array Etalon Spectrometer (CLAES, vertical resolution $\sim 2.5 \mathrm{~km}$ ), and CRyogenic Infrared Spectrometers and Telescopes for the Atmosphere (CRISTA, vertical resolution $\sim 3 \mathrm{~km}$ ) have led to important developments in the study of stratospheric Kelvin waves (Salby et al. 1984, 1990; Canziani et al. 1994, 1995; Shiotani et al. 1997; Canziani 1999; Smith et al. 2002). These satellite-based studies indicate that most Kelvin wave variability in the middle atmosphere is contained in the zonal wavenumber range of $1-3$. Temperature measurements with very high vertical resolution $(\sim 100 \mathrm{~m})$ and global coverage in the troposphere and lower stratosphere have become possible with GPS RO method. GPS RO is a space-borne remote sensing technique providing accurate, all-weather, and high vertical resolution profiles of atmospheric parameters (Melbourne et al. 1994). The proof-of-concept GPS/Meteorology (GPS/MET) experiment performed between 1995 and 1997 by the University Center for Atmospheric Research (UCAR) demonstrated the potential of GPS-based limb sounding from low-Earth orbit (LEO) satellites for the first time. This experiment provided high-resolution data set of temperature, pressure and refractivity profiles in the $1-60 \mathrm{~km}$ altitude range. Followon GPS RO experiments including CHAllenging Mini satellite Payload (CHAMP; Wickert et al. 2001) and Satellite de Aplicaciones Cientificas-C (SAC-C; Hajj et al. 2004) have also provided high resolution atmospheric data. By using GPS/MET temperature profiles, Tsuda et al. (2000) extracted temperature fluctuations at short vertical wavelengths to address the global morphology of gravity wave activity in the stratosphere. As per the available literature survey, Tsai et al. (2004) were the first to identify slow Kelvin waves in the tropical UTLS by analyzing the temperature profiles retrieved using CHAMP as well as SAC-C GPS RO experiments. Complementing Tsai's work, Randel and Wu (2005) and Ratnam et al. (2006) have also shown evidence of Kelvin waves in temperature data derived from CHAMP and SAC-C GPS RO.

In our present study, we investigate Kelvin wave characteristics and their seasonal variability using GPS RO temperature data derived from the Constellation Observation System for Meteorology, Ionosphere and Climate (COSMIC)/Formosa Satellite 3 (FORMOSAT-3; Rocken et al. 2000), which produces $\sim 12$ times more data than its counterpart GPS RO mission CHAMP. It is expected that F3/C may provide much more detailed analysis of wave structures. Further, the unique feature of F3/C GPS RO technique is that it has been implemented with an open loop (OL) tracking (which is model-based and works on real-time navigation solution), which could significantly improve the ability to probe deeper into the lower troposphere and planetary boundary layer and also enables the acquisition of rising GPS signals for the first time, thereby doubling the number of occultations as collected by a GPS receiver in LEO. In contrast, previous GPS RO missions including GPS/MET, CHAMP and SAC-C (until 2005) worked on closed-loop (CL) tracking mode, in which the receiver uses a phase-locked-loop (PLL) and this method often fails in the presence of low signal-to-noise ratio (SNR) and high signal dynamics. Ao et al. (2009) provides a complete understanding of the OL tracking technique routinely applied on COSMIC. This article is organized as follows: in section 2, data analysis and the methodology adopted in this study are furnished. The observational results are given in section 3. A discussion along with summary of this study's results are presented in section 4 .

\section{DATA ANALYSIS AND METHODOLOGY}

\subsection{Kelvin Wave Identification Procedure}

$\mathrm{F} 3 / \mathrm{C}$ is a joint US-Taiwan mission consisting of six identical micro-satellites launched from Vandenberg Air Force Base California in a circular inclination $\left(72^{\circ}\right)$ orbit at an altitude of $512 \mathrm{~km}$ on 15 April 2006 (Cheng et al. 2006). During the first 17 months following the launch, the satellites were gradually dispersed in their final orbits at $\sim 800 \mathrm{~km}$, with a separation angle between neighboring orbital planes of $30^{\circ}$ longitude. The current and near-final orbital configuration gives global coverage of approximately 2000 soundings per day, distributed near uniformly in local solar time. In our study, we use F3/C GPS RO retrieved temperature profiles between $\pm 5^{\circ}$ latitudes around the equator (since Kelvin waves are concentrated around the equator; Mote et al. 2002) starting from September 2006 to February 2008 to study Kelvin wave activity. Figure 1 depicts the number of radio occultations from the F3/C GPS RO 
technique for the study period. The total number of occultations during this time period is 28623 which means that on an average there were $\sim 1500$ occultations per month i.e., 50 occultations per day were available in this narrow latitudinal range $\left(+5^{\circ} \mathrm{N}\right.$ and $\left.+5^{\circ} \mathrm{S}\right)$.

The following procedure has been adopted to extract Kelvin characteristics in the F3/C temperature profiles. In the first step, the temperature data has been interpolated to $0.5 \mathrm{~km}$. It is to be noted that the original F3/C data are available at $0.1 \mathrm{~km}$ vertical resolution and have an effective vertical resolution on the order of $0.5 \mathrm{~km}$ or above in the UTLS and stratospheric region. Due to the high inclination $\left(72^{\circ}\right)$ orbit of F3/C satellites, the temperature profiles data occurrence rates around the equator are rather sparse and hence an interpolation (cubic) method in longitude has been applied on the temperature profile data to fill-in the missing data starting from 5 to $30 \mathrm{~km}$ altitudes. Figure 2a shows the typical F3/C derived temperature profile on 1 December 2006 (latitude $4.83^{\circ} \mathrm{N}$, longitude $156.99^{\circ} \mathrm{W}$ ), while Fig. $2 \mathrm{~b}$ shows the longitudinal temperature profile (blue stars) at $17 \mathrm{~km}$ on 2 September 2006 over the entire equatorial region and cubic interpolation data $(\mathrm{T})$ (blue solid line) along with $3^{\text {rd }}$ order polynomial fit (red solid line). In the second step, we use a $3^{\text {rd }}$ order polynomial $\left(\mathrm{T}_{0}\right)$ to best fit to the interpolated data, which is considered to be background temperature variation. The background values were then removed from each temperature profile corresponding to each altitude and the resulting fluctuation $\left(\mathrm{T}^{\prime}=\mathrm{T}-\mathrm{T}_{0}\right)$ data has been utilized to identify the Kelvin wave features. Furthermore, fluctuation data during every three month period are put together as ensembles to show the seasonal variation of Kelvin wave activity for Fall (SON), Winter (DJF), Spring (MAM) and
Summer (JJA) of 2006 and 2007 respectively. Figure 3a shows interpolated data for Fall 2006 at $17 \mathrm{~km}$ altitude and Fig. 3b shows the removed background (fluctuation) data during same period for the entire globe. The dominance of Kelvin wave-like features that appear in fluctuation components during the Fall 2006 season has been highlighted with a black rectangular box (Fig. 3b). As a final step, we applied a Fast Fourier Transform (FFT) on large scale temperature fluctuation components and the subsequent application of incoherent integration on the output of the FFT to identify the typical characteristics of Kelvin waves. Since a low-pass filter was not applied in the vertical and zonal direction of the temperature fluctuation components, the contribution of small scale variations such as gravity wave components

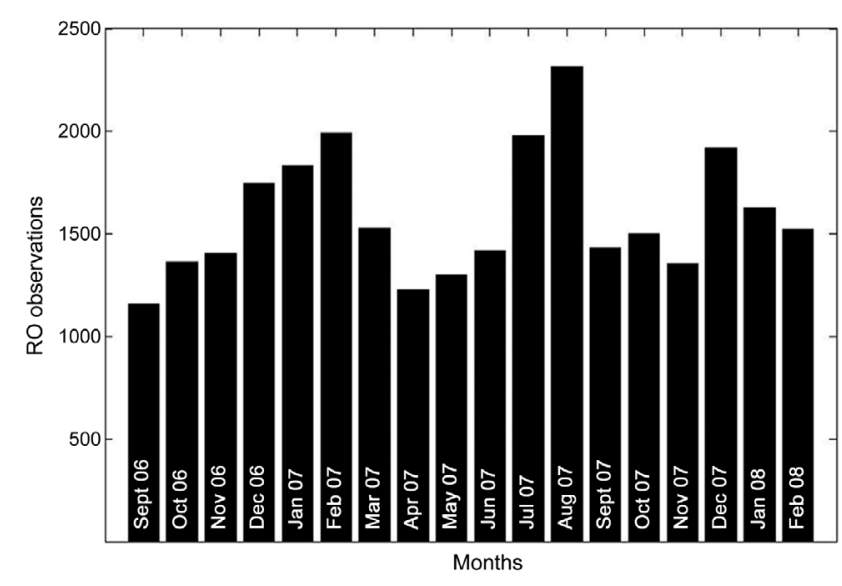

Fig. 1. Bar graph showing number of FORMOSAT-3/COSMIC GPS RO observations in a narrow latitudinal range between $5^{\circ} \mathrm{N}$ and $5^{\circ} \mathrm{S}$ during the study period. (a) 2006.12.1 temperature data Lat $=4.8324$, Lon $=-156.9932$

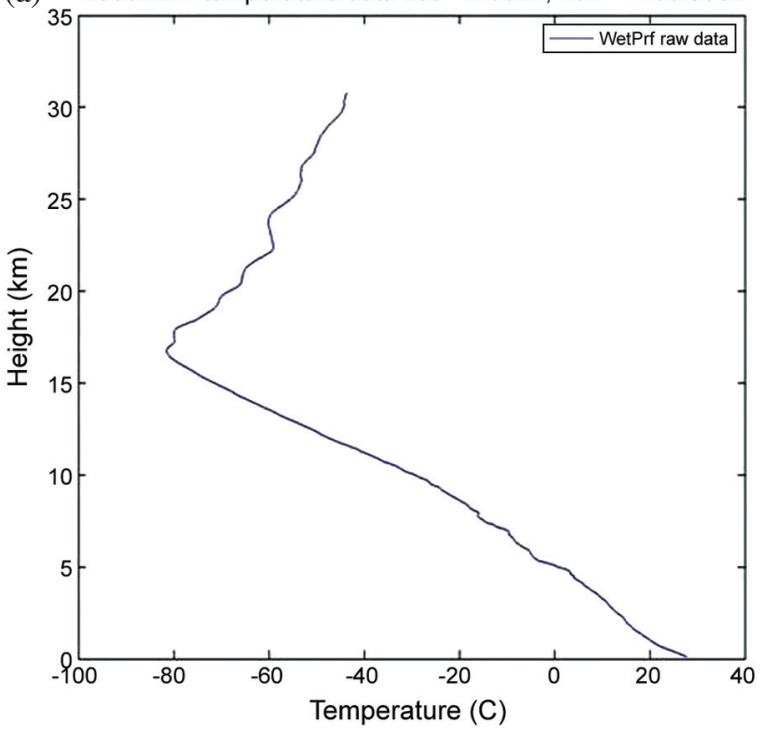

(b) COSMIC WetPrf 2006.9.2 $17 \mathrm{~km}$ Equatorial temperature data

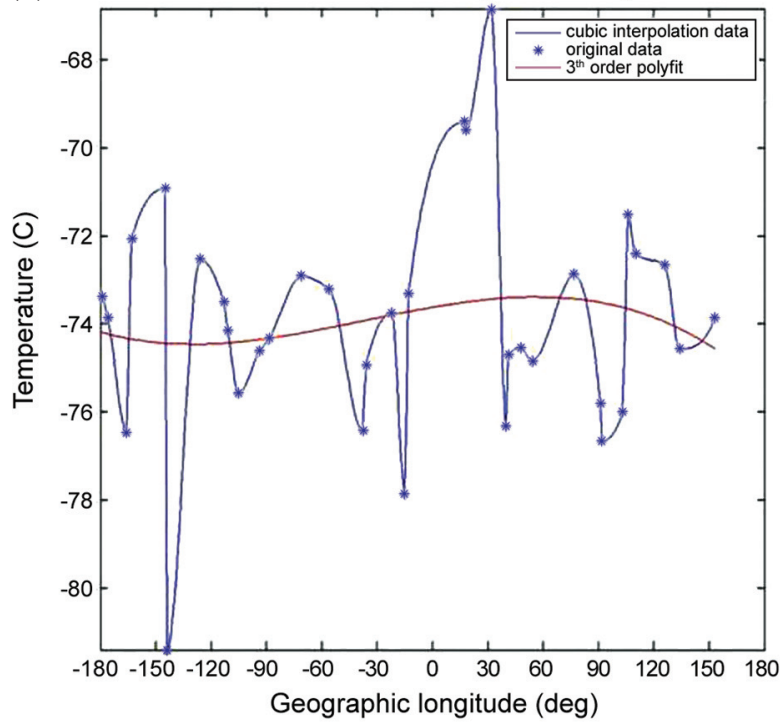

Fig. 2. (a) FORMOSAT-3/COSMIC GPS RO retrieved temperature data on 1 December 2006; (b) Temperature fluctuation data (blue color stars) at $17 \mathrm{~km}$ on 2 September 2006 along with cubic interpolation data (blue color solid line) and $3^{\text {rd }}$ order polynomial fit (red color solid line). 
(a)

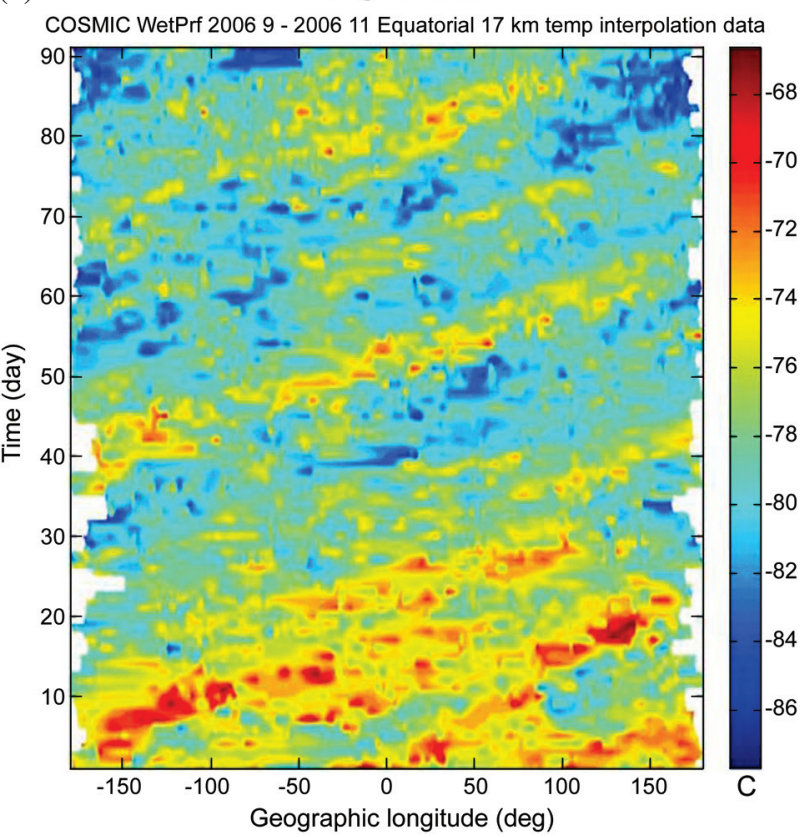

(b)

Background removed data

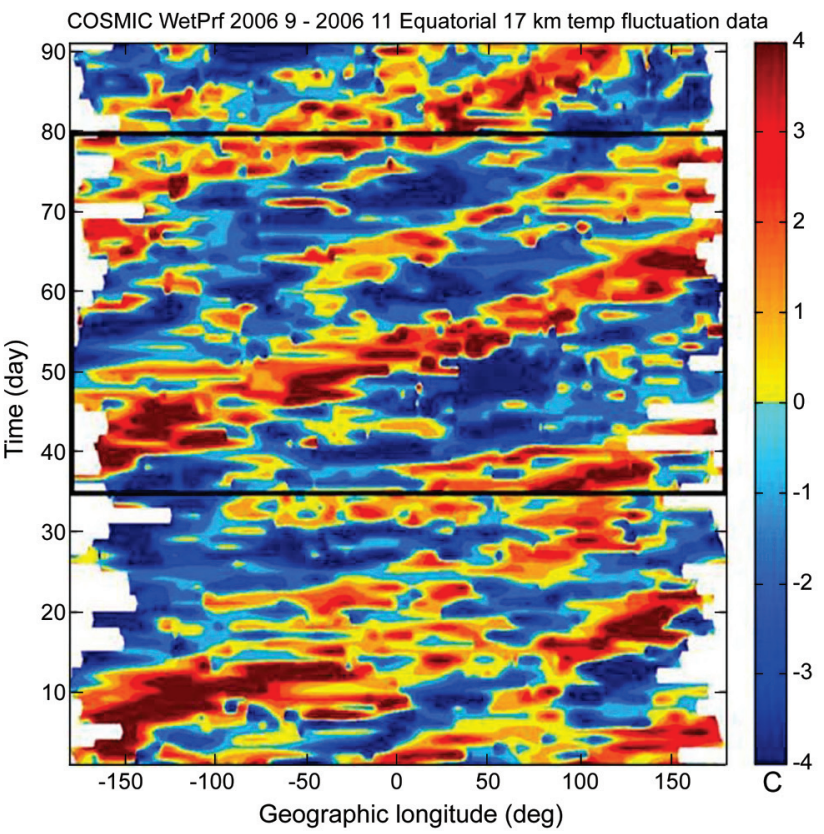

Fig. 3. (a) Cubic interpolation data for Fall 2006; (b) background removed data during the same season. The dominance of Kelvin waves is marked with black color rectangular box.

(Tsuda et al. 2000) would also be present in the fluctuation components. Because of the inherent characteristics of Kelvin waves including eastward propagation and global scale zonal wavenumber, the identification of Kelvin waves in the fluctuation components is possible without ambiguity.

The wind data obtained from radiosonde measurements over an equatorial station in Singapore $\left(1^{\circ} \mathrm{N}, 104^{\circ} \mathrm{E}\right)$ have been utilized as background wind information. Further, daily gridded outgoing long-wave radiation (OLR) data provided by the National Oceanic and Atmospheric Administration (NOAA) Climate Diagnostics Center (http://www. cdc.noaa.gov) is used as a proxy for tropical deep convection in the present study.

\section{RESULTS}

\subsection{Long-Period Waves}

Figure 4 depicts the longitude-time diagrams of temperature fluctuations at $17 \mathrm{~km}$ (Figs. 4a and b) and $19 \mathrm{~km}$ (Figs. 4c and d) during September 2006 to February 2007. The temperature fluctuations from November 2006 to February 2007 at $17 \mathrm{~km}$ are characterized by the known climatological structure of cold temperatures over longitudes $\sim 90-200^{\circ} \mathrm{E}$ and associated with maximum convection over Indonesia (Highwood and Hoskins 1998; Seidel et al. 2001; Randel et al. 2003; Randel and Wu 2005). The temperature minimum in the cold region varies episodically during these months (in response to variations in deep convection), but overall the patterns are quasi-stationary. In contrast, tem- perature fluctuations at $19 \mathrm{~km}$ show zonal wavenumber-1 structure with regular eastward propagation. These observational results are consistent with earlier reported results including Garcia and Salby (1987) and Randel and Wu (2005). Randel and Wu (2005) using CHAMP and SAC-C RO data have found the quasi-stationery wave structures near the tropopause $(17 \mathrm{~km})$ for six consecutive months starting from October 2001 to March 2002 (Fig. 4a of their paper) and regular eastward propagating waves at $19 \mathrm{~km}$ (Fig. $4 \mathrm{~b}$ of their paper). The monthly-mean zonal (east-west) winds at $10-30 \mathrm{~km}$ presented in Fig. 5 for the period March 2006 to August 2008 shows the dominance of stratospheric QBO with downward phase propagation particularly from $17 \mathrm{~km}$ onwards and above with dominant amplitude at 27 - $29 \mathrm{~km}$. The double headed arrow in this figure indicates the time period (September 2006 to February 2008) during which the characteristics of Kelvin waves are studied. Note that the time period of the present study includes almost one complete cycle of QBO with the eastward phase starting from March 2006 to May 2007 and westward phase from June 2007 to July 2008. It is also obvious from Fig. 5 that the westward winds are always noticed below $\sim 17 \mathrm{~km}$ with maximum amplitudes in between 15 and $14.5 \mathrm{~km}$. In order to verify the Kelvin wave activity in the presence of both phases of QBO, vertical waves of temperature fluctuation components are selected and presented in Fig. 6, for four days: (1) 13/14 October 2006 (Fig. 6a: eastward phase), (2) 15/16 May 2007 (Fig. 6b: eastward phase), (3) 27/28 August 2007 (Fig. 6c: westward phase), and (4) 19/20 February 

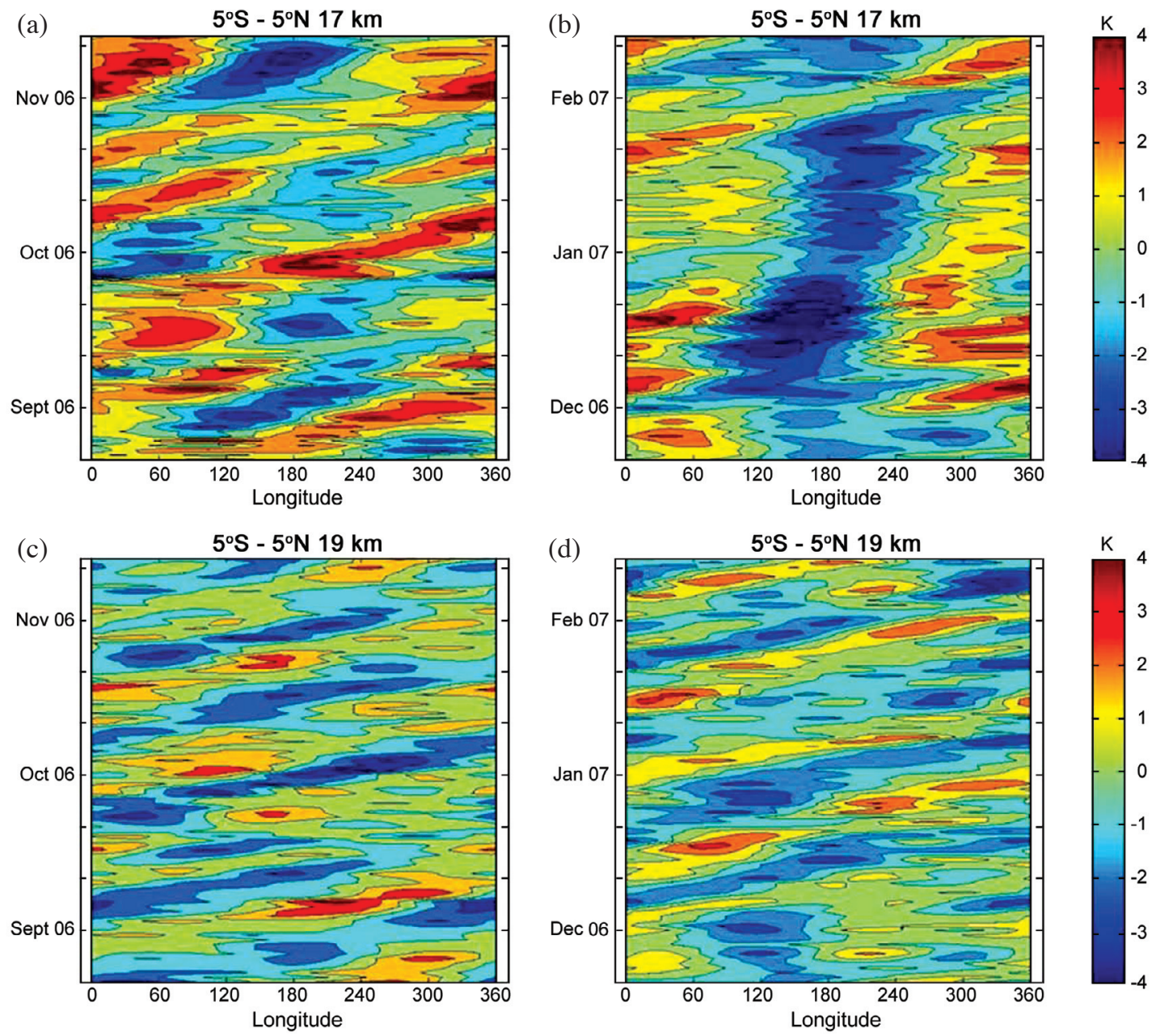

Fig. 4. Longitude-time diagrams of temperature fluctuations over $5^{\circ} \mathrm{S}-5^{\circ} \mathrm{N}$ during (a) September to November 2006 and (b) December 2006 to February 2007 at 17 km, and (c) September to November 2006 and (d) December 2006 to February 2007 (d) at 19 km.

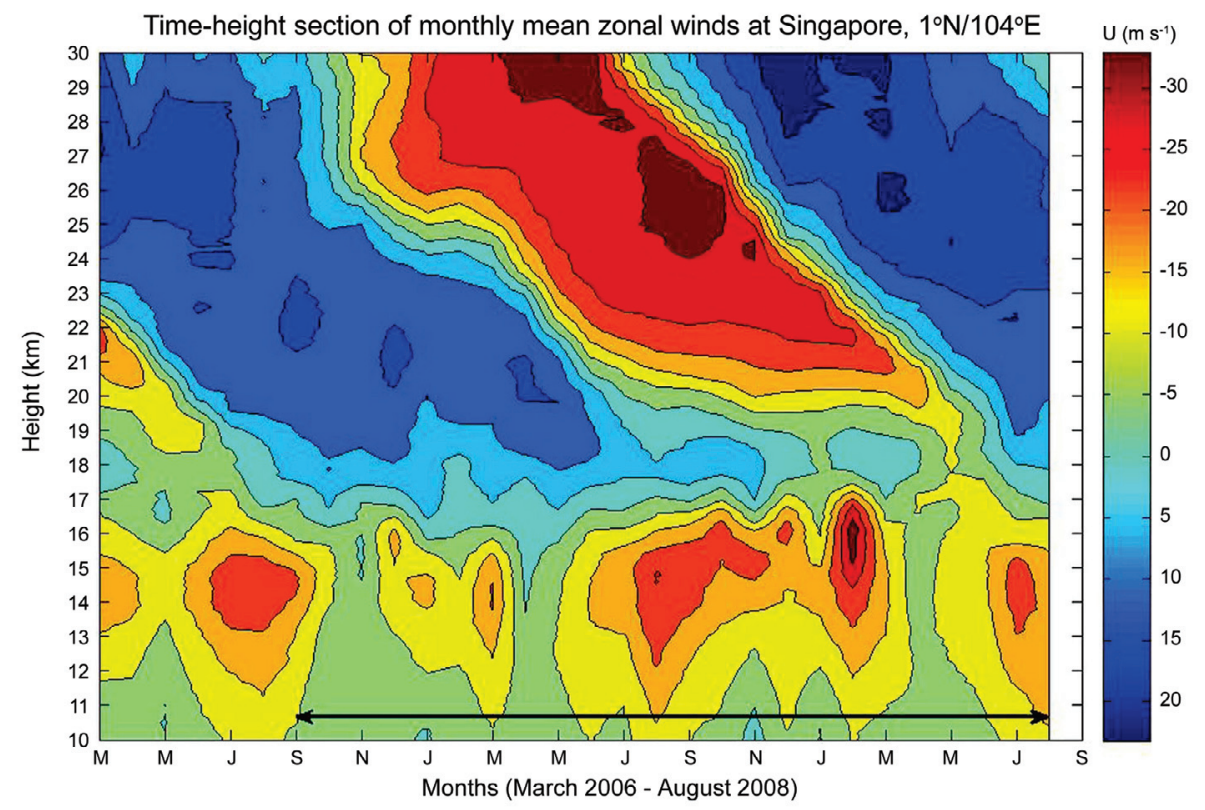

Fig. 5. Zonal winds derived from radiosonde measurements over Singapore from March 2006 - August 2008 which clearly indicates the stratospheric QBO feature. 
(a) Temperature fluctuation data 200610 Day $13-14$
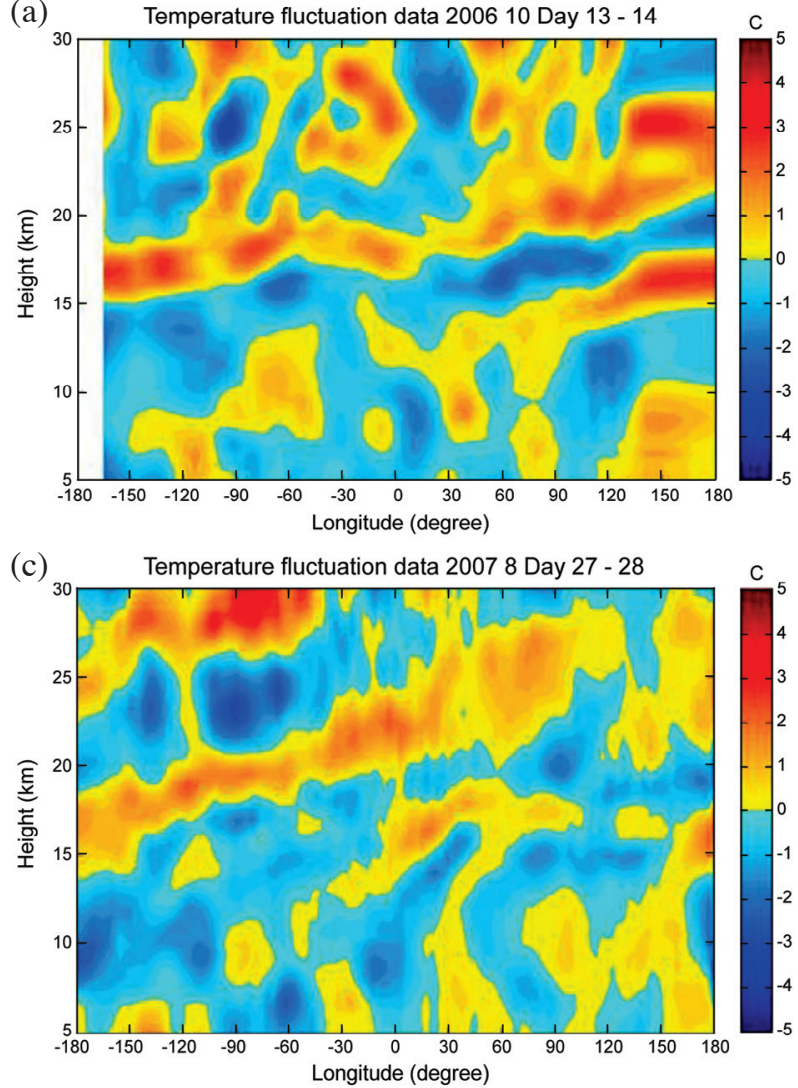
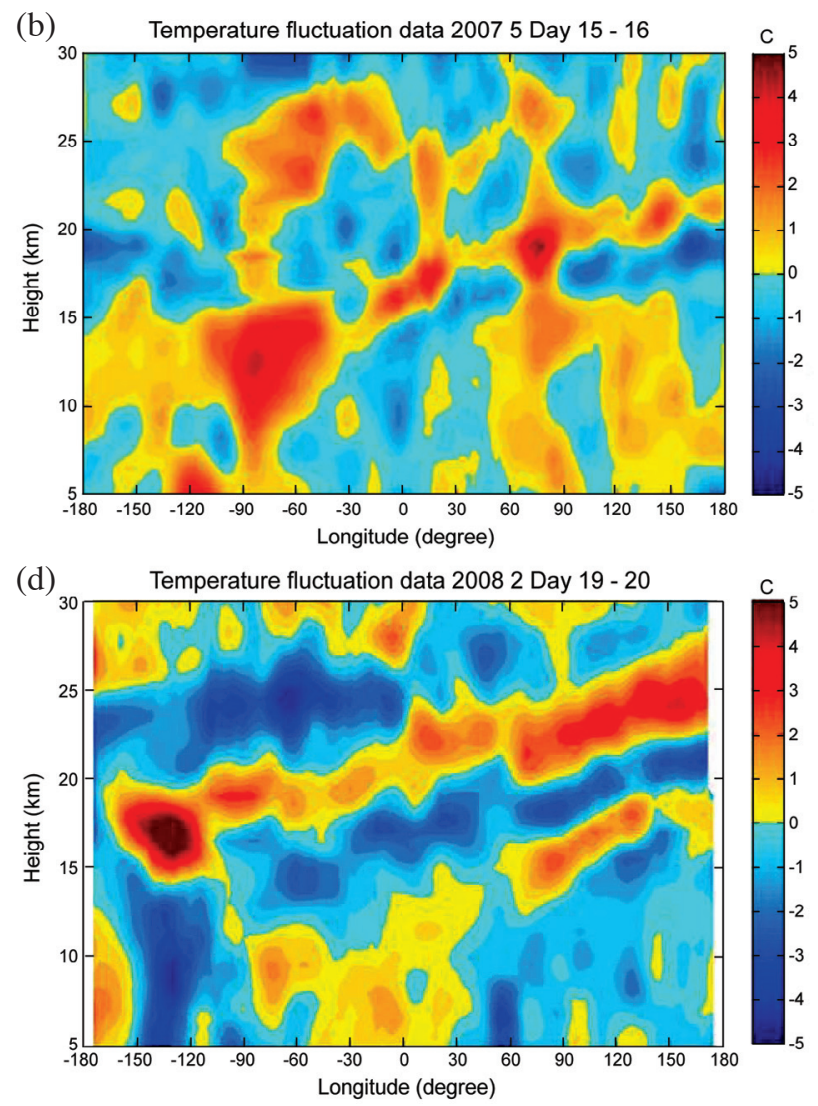

Fig. 6. Kelvin wave signatures in temperature fluctuations during eastward phase [(a), (b)] and westward phase [(c), (d)] of QBO.

2008 (Fig. 6d: westward phase) respectively. It is obvious that the eastward phase tilt with height (characteristic of Kelvin waves) is evident in all figures with coherent vertical structure over $\sim 11-27 \mathrm{~km}$ and largest amplitudes near and above the tropical tropopause. Figure 7 depicts the monthly averaged tropopause height derived from temperature profiles of F3/C data from September 2006 to February 2008. Vertical wavelengths in Figs. $6 \mathrm{a}$ and $\mathrm{b}$ are found to be $\sim 10$ and $12 \mathrm{~km}$, while the phase lines of temperature waves in Figs. $6 \mathrm{c}$ and $\mathrm{d}$ are extending into the upper troposphere with more upright behaviour with longer vertical wavelengths around 13 and $14 \mathrm{~km}$. The plausible physical mechanism behind these interesting observational results, i.e., the increased (decreased) characteristic of Kelvin wave activity during QBO westward (eastward) phase is discussed later (in section 4). Further, the Kelvin wave event shown in Fig. 6d is relatively stronger than its counterpart events.

In order to verify the detailed space-time characteristics of Kelvin waves, we have constructed height-time variations of temperature fluctuations during different seasons starting from September 2006 to February 2008. Figure 8 shows the height/time variations of temperature fluctuations at random longitudes (Figs. 8a - f corresponding to Fall 2006, Winter 2006, Spring 2007, Summer 2007, Fall 2007, and Winter 2007, respectively). It should be noted that Kelvin wave fea- tures in these panels are marked with slanted black lines for the sake of easy identification. The interesting feature from these figures is that Kelvin events started below the tropopause height (around $13 \mathrm{~km}$ ) and extends as high as $28 \mathrm{~km}$ and the vertical wavelengths are found to be as low as $5 \mathrm{~km}$ during Spring 2007 (Fig. 8c) and as high as $12 \mathrm{~km}$ during Summer 2007 (Fig. 8d). The vertical wavelengths observed here are in good agreement with those observed using high-

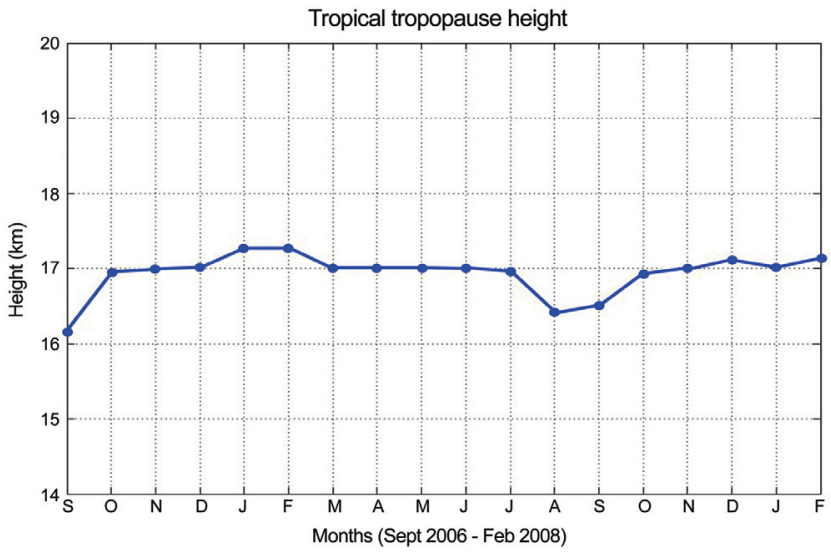

Fig. 7. Mean height of tropical tropopause from September 2006 to February 2008. 

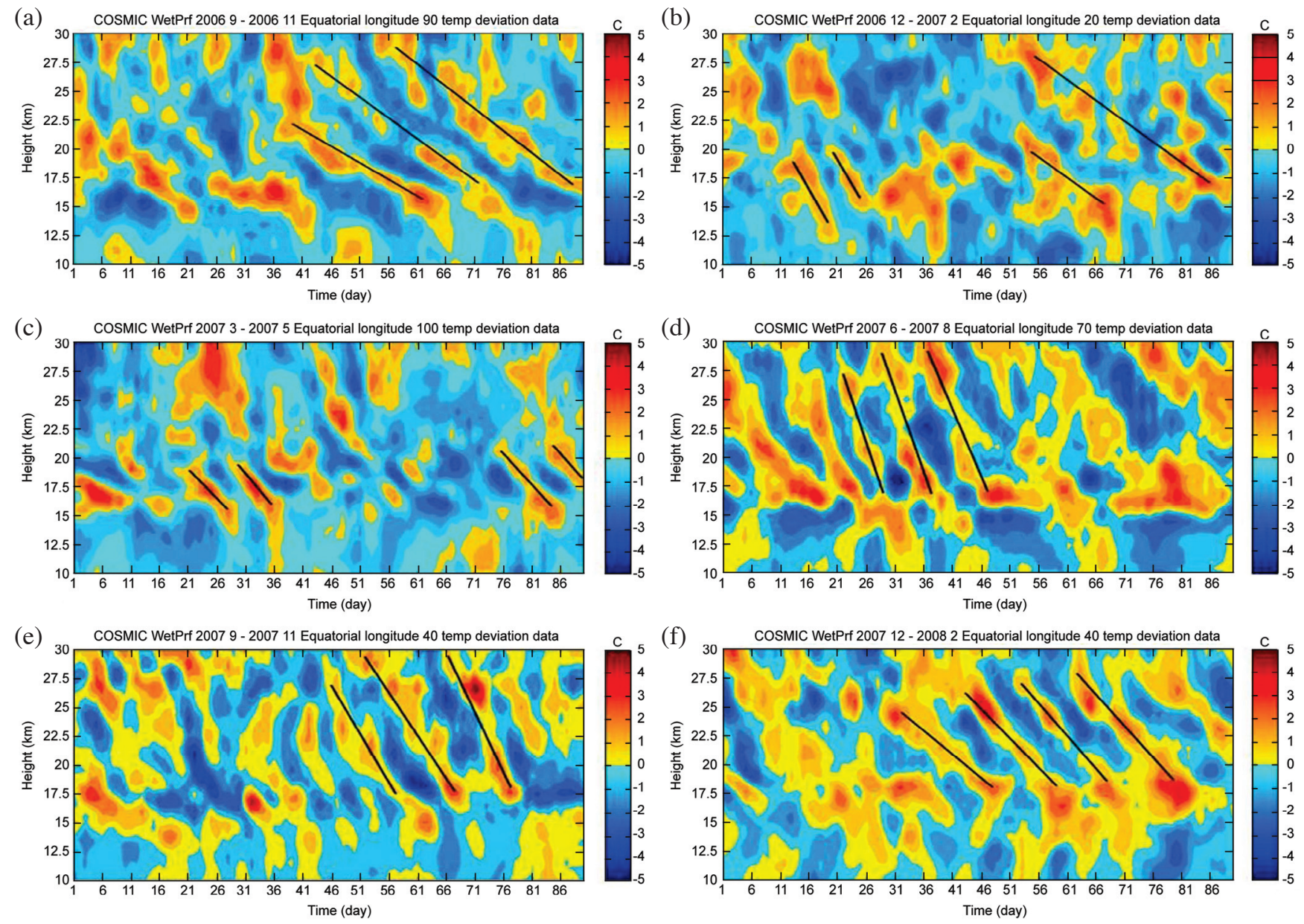

Fig. 8. Kelvin wave signatures during different seasons from Fall 2006 to Winter 2007 [(a) - (f)].

vertical resolution radiosonde measurements by Tsuda et al. (1994; vertical wavelengths: $5-6 \mathrm{~km}$ ) and Sridharan et al. (2006; $5.5-6.5 \mathrm{~km})$ and also by Tsai et al. (2004; 7.6 $8.5 \mathrm{~km}$ for $\mathrm{s}=1$ and $4.4-5.8 \mathrm{~km}$ for $\mathrm{s}=2$ ), Randel and $\mathrm{Wu}$ (2005; $4-8 \mathrm{~km})$ with CHAMP and SAC-C GPS RO measurements, and Ratnam et al. (2006; 5 - 8 km) with CHAMP RO measurement. In addition, the downward phase progression is evident in all the cases suggesting that the possible source of these waves could be from lower altitudes possibly due to tropospheric convective heating. It is obvious from Fig. 8 that the overall space-time characteristics of the planetary-scale equatorial waves in GPS data are consistent with Kelvin waves. Kelvin waves satisfy the linear dispersion relation for eastward propagating hydrostatic gravity waves (Andrews et al. 1987). The dispersion formula (Holton et al. 2001) can be expressed as

$L_{z}=\frac{2 \pi}{N}\left(\frac{L_{x}}{\tau}-\bar{u}\right)$

where $\bar{u}, N, \tau, L_{x}$, and $L_{z}$ are velocity of mean zonal wind (calculated from radiosonde measurement over Singapore), buoyancy frequency (equal to $0.02 \mathrm{~m} \mathrm{~s}^{-1}$ ), wave period (observed parameter), zonal wavelength (it is $40200 \mathrm{~km}$ for wave 1 and $20100 \mathrm{~km}$ for wave 2) and vertical wavelength (observed parameter) respectively. It is thus possible for one to check whether the observed waves fit the Kelvin wave dispersion relation for the given observed periods and vertical wavelengths. Both observational and theoretical vertical wavelengths show higher coherence during most of the seasons (except Winter 2007), which greatly enhances the confidence in our observational methodology.

The validation of F3/C GPS RO retrieved temperatures was provided by near-coincident comparisons with radiosonde temperature measurements at Singapore $\left(1^{\circ} \mathrm{N}, 104^{\circ} \mathrm{E}\right)$ as shown in Fig. 9. Figure 9a shows the typical temperature profile of F3/C (thick blue line) and near-by radiosonde temperature (thin black line) on 18 October 2006 and Fig. 9b shows another comparison on 14 November 2006. It is clear from these figures that the vertical temperature profiles show good agreement between these two measurements. Figure 10 shows a longitude-time diagram of the OLR data, averaged over $5^{\circ} \mathrm{N}-5^{\circ} \mathrm{S}$, from September 2006 to August 2008. It should be noted that the daily OLR data are avail- 
(a) Radiosonde and GPS 18 October 2006

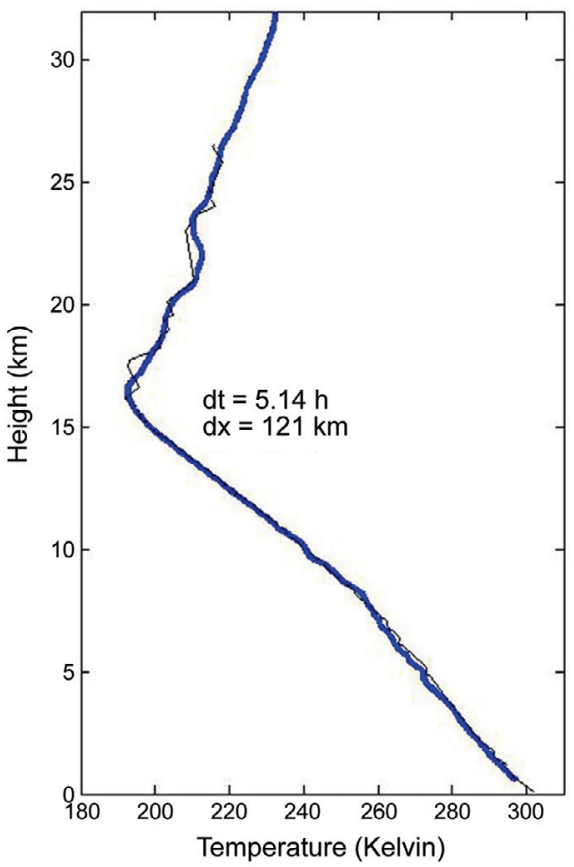

(b) Radiosonde and GPS 14 November 2006

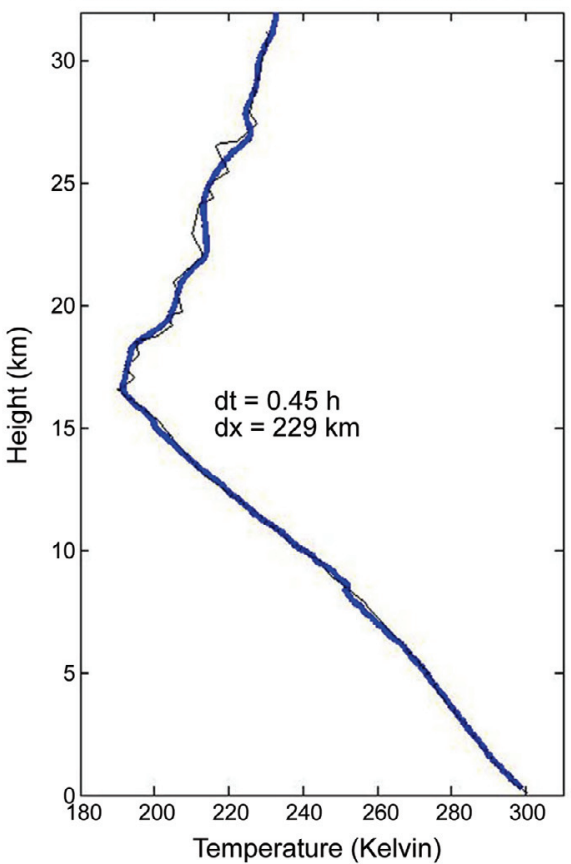

Fig. 9. Vertical profiles of temperatures from Singapore radiosonde measurements (thin lines) and nearby GPS retrievals (thick lines). These comparisons are shown for (a) 18 October 2006 and (b) 14 November 2006.

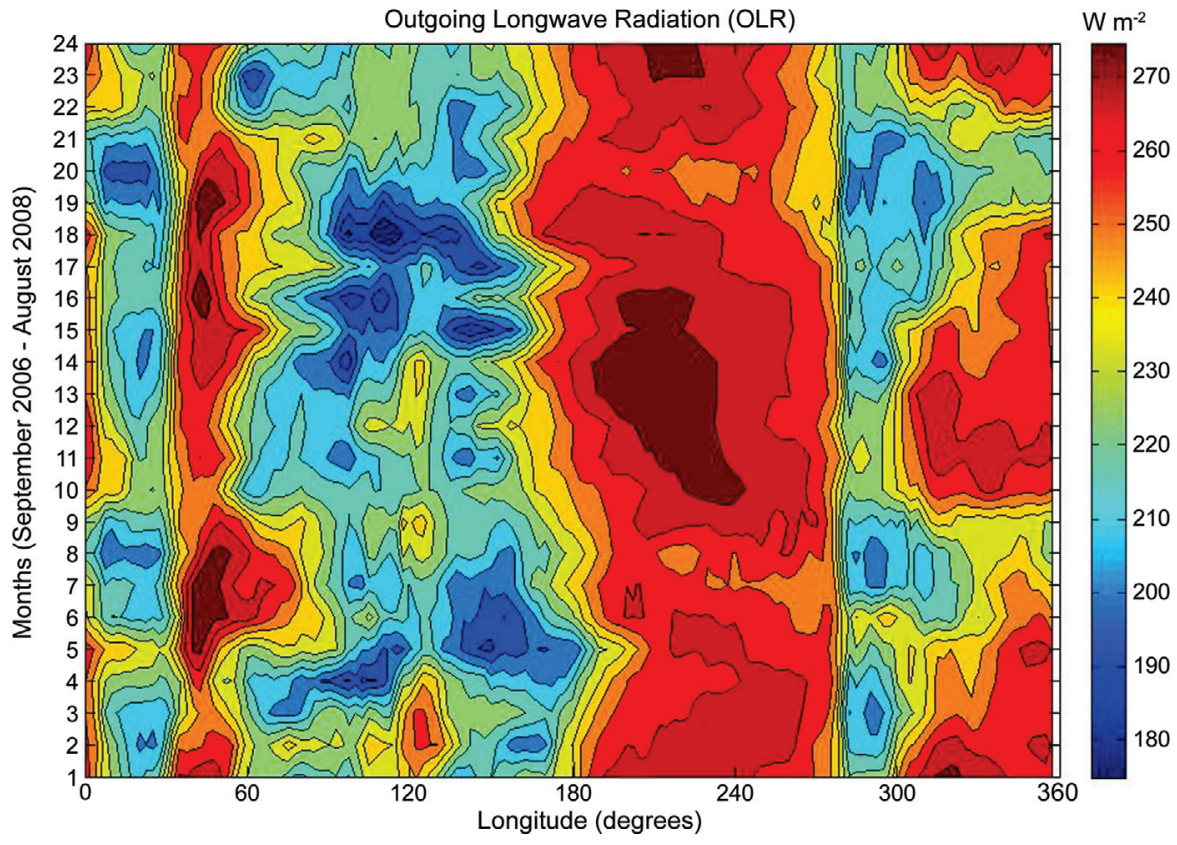

Fig. 10. OLR data averaged between $5^{\circ} \mathrm{N}$ and $5^{\circ} \mathrm{S}$ from September 2006 to August 2008.

able on a $2.5^{\circ}$ latitude-longitude grid, with data gaps filled by linear interpolation to provide complete sampling. It is obvious from this figure that three regions including $\sim 10$ $30^{\circ} \mathrm{E}, \sim 60-170^{\circ} \mathrm{E}$, and $\sim 280-310^{\circ} \mathrm{E}$ are characterized by relatively low OLR values, often reaching less than $180 \mathrm{~W}$ $\mathrm{m}^{-2}$ particularly over $\sim 60-170^{\circ} \mathrm{E}$, compared to the rest of the globe. Table 1 shows different characteristics of Kelvin waves including wavenumber $(\mathrm{s})$, wave period $(\tau)$ in days, phase speed ( $C_{x}=L_{x} / \tau$, where $L_{x}$ is the zonal wavelength for wavenumber one is equivalent to $40200 \mathrm{~km}$, which is the circumference of the Earth over the equator), and the vertical wavelength $\left(L_{z}\right)$ observed during different seasons 
Table 1. Summary characteristics of Kelvin waves.

\begin{tabular}{lcccccc}
\hline & Fall 2006 & Winter 2006 & Spring 2007 & Summer 2007 & Fall 2007 & Winter 2007 \\
\hline Wave number (s) & 1 & 1 & 2 & 1 & 2 & 1 \\
Wave period (days) $(\tau)$ & 15 & 17 & 10 & 17 & 9.5 & 15 \\
Phase speed $\left(\mathrm{km} \mathrm{hr}^{-1}\right)\left(C_{x}\right)$ & 75.6 & 92.6 & 83.3 & 87.5 & 77.5 & 86.8 \\
Vertical wavelength $(\mathrm{km})\left(L_{z}\right)$ & $5-6$ & $6-8$ & $5-8$ & $6-12$ & $6-10$ & $6-7$ \\
Theoretical $L_{z}(\mathrm{~km})$ & 5.02 & 5.45 & 4.8 & 7.3 & 9.2 & 12.0 \\
\hline
\end{tabular}

of 2006 - 2007 and provided theoretically computed (using the dispersion relation of Kelvin waves and the mathematical formula of this will be discussed in the section 4 of this paper) vertical wavelengths at the bottom column of Table 1. As summarized by Canziani et al. (1994), Kelvin waves are associated with three discrete temporal bands including slow (phase speeds of $20-40 \mathrm{~m} \mathrm{~s}^{-1}$ and vertical wavelength $\sim 10 \mathrm{~km})$, fast (50 - $\left.80 \mathrm{~m} \mathrm{~s}^{-1}, \sim 20 \mathrm{~km}\right)$, and ultrafast $\left(\sim 80 \mathrm{~m} \mathrm{~s}^{-1}\right.$, $\sim 40 \mathrm{~km}$ ). Since the phase speed and vertical wavelength of Kelvin waves during different seasons (Table 1) found in this study lie roughly between $21-26 \mathrm{~m} \mathrm{~s}^{-1}$ and $5-12 \mathrm{~km}$ respectively, it can easily be concluded that the observed waves belong to slow wave category.

\section{DISCUSSION AND SUMMARY}

Using temperature fields retrieved from F3/C GPS RO technique in the equatorial UTLS for different seasons during 2006 - 2007, we have objectively identified the leading Kelvin wave modes of wavenumber 1 and 2 variability in equatorial temperatures. The tropospheric Kelvin waves can significantly affect the behaviour of tropical troposphere including its height (Randel and Wu 2005), temperature and sharpness (Ratnam et al. 2006). The quasi-stationery waves reported in this paper over $90-200^{\circ} \mathrm{E}$ longitudes at $17 \mathrm{~km}$ (Figs. 4a and b) could act as additional source in modulating the tropical tropopause (Randel and Wu 2005; Ratnam et al. 2006). Another striking feature of our study is that the Kelvin wave activity is enhanced or decreased during the corresponding westward or eastward phase of the QBO (Fig. 5), which is consistent with previously reported results including Tsai et al. (2004), Randel and Wu (2005) and Ratnam et al. (2006). The strong relation between Kelvin waves and background winds is most likely due to the thermal damping as proposed by Shiotani and Horinouchi (1993). Furthermore, since the tropical Kelvin waves are primarily forced by transient deep convection (as discussed in Section 1), we have studied this relationship using global OLR data as a proxy for deep convective activity. The most variable and intense deep convection (Fig. 10) is noted in between $\sim 60$ and $170^{\circ} \mathrm{E}$ longitudes with significant enhancements during the Northern Hemisphere's winter months from November 2006 to January 2007 and much of the variability during this period appears in slowly eastward propagating features (phase speeds $\leq 5 \mathrm{~m} \mathrm{~s}^{-1}$ ). Further, climatological structure of the cold temperatures at $17 \mathrm{~km}$ in temperature fluctuations noticed from November 2006 to February 2007 over $\sim 90-200^{\circ} \mathrm{E}$ longitude, which are associated with convection activity (Highwood and Hoskins 1998; Randel et al. 2003; Randel and Wu 2005) as discussed earlier. From the above observational results and previous studies, it is conceivable that the tropical convection generated over Indonesia region during the present observation period could be the plausible source mechanism for Kelvin waves (Salby and Garcia 1987; Wheeler and Kiladis 1999). However, the phase speed of travelling OLR patterns (shown in Fig. 10) is much slower than the Kelvin waves observed in this study, so that the latter are not continuously coupled to convection. Rather, the observed Kelvin waves are more consistent with free modes forced by the broad spectrum of convective variability, especially that over the active Indonesian region.

We summarize the salient results of the present study as follows:

(1) The temperature fluctuation waves appearing in the GPS RO derived temperatures have a characteristic eastward phase tilt with height in longitude-altitude and eastward phase propagation in longitude-time sections with wave periods greater than 10 days, which are the typical characteristics of slow Kelvin waves.

(2) The temperature fluctuation waves are often quasi-stationary near the tropopause and exhibit regular eastward propagation in the lower stratosphere.

(3) Typical comparisons between vertical temperature profiles derived from COSMIC GPS RO data and near-by radiosonde measurements reveal high coherency which provide confidence in the global patterns derived from GPS data.

(4) The predominant Kelvin wave(s) observed in the temperature fluctuations are in the altitude range between $15-28 \mathrm{~km}$ centered on the tropical tropopause. 
(5) The Kelvin wave activity is found to be enhanced during the westward phase of the QBO which diminishes during the eastward phase.

(6) The OLR data confirms that a deep tropical convection developed over the Indonesian region during the present observation period and might be the likely source of these Kelvin waves.

(7) A comparison between observed and calculated vertical wavelengths of the Kelvin waves revealed that both have a higher correspondence during most of the seasons indicating a measure of reliability in the present data analysis and methodology in extracting the eastward propagating waves.

Acknowledgements $\mathrm{F} 3 / \mathrm{C}$ temperature data were obtained from the COSMIC Data Analysis and Archive Centre (CDAAC). This work was supported by the National Space Program Office (NSPO) of the Republic of China under the grants 97-NSPO (B)-SP-FA07-02 (A). We wish to thank Dr. Smitha V Thampi, JSPS fellow, RISH, Kyoto University, Japan for useful discussions and advice.

\section{REFERENCES}

Alexander, M. J. and J. R. Holton, 1997: A model study of zonal forcing in the equatorial stratosphere by convectively induced gravity waves. J. Atmos. Sci., 54, 408419, doi: 10.1175/1520-0469(1997)054<0408:AMSO $\mathrm{ZF}>2.0 . \mathrm{CO} ; 2$. [Link]

Alexander, S. P., T. Tsuda, Y. Kawatani, and M. Takahashi, 2008: Global distribution of atmospheric waves in the equatorial upper troposphere and lower stratosphere: COSMIC observations of wave mean flow interactions. J. Geophys. Res., 113, D24115, doi: 10.1029/20 08JD010039. [Link]

Andrews, D. G., J. R. Holton, and C. B. Leovy, 1987: Middle Atmospheric Dynamics, Academic Press, 489 pp.

Angell, J. K. and J. Korshover, 1964: Quasi biennial oscillations in temperature, total ozone and tropopause height. J. Atmos. Sci., 21, 479-492.

Ao, C. O., G. A. Hajj, T. K. Meehan, D. Dong, B. A. Iijima, A. J. Mannucci, and E. R. Kursinski, 2009: Rising and setting GPS occultations by use of openloop tracking. J. Geophys. Res., 114, D04101, doi: 10.1029/2008JD010483. [Link]

Baldwin, M. P., L. J. Gray, T. J. Dunkerton, K. Hamilton, P. H. Haynes, W. J. Randel, J. R. Holton, M. J. Alexander, I. Hirota, T. Horinouchi, D. B. A. Jones, J. S. Kinnersley, C. Marquardt, K. Sato, and M. Takahashi, 2001: The quasi-biennial oscillation. Rev. Geophys., 39, 179-229.

Canziani, P. O., 1999: Slow and ultraslow equatorial Kelvin waves: The UARS CLAES view. Q. J. R. Meteorol. Soc., 125, 657-676, doi: 10.1002/qj.49712555414.
[Link]

Canziani, P. O. and J. R. Holton, 1998: Kelvin waves and the quasi-biennial oscillation: An observational study. J. Geophys. Res., 103, 31509-31521, doi: 10.1029/19 98JD200021. [Link]

Canziani, P. O., J. R. Holton, E. Fishbein, L. Froidevaux, and J. W. Waters, 1994: Equatorial Kelvin waves: A UARS MLS view. J. Atmos. Sci., 51, 3053-3076, doi: 10.1175/1520-0469(1994)051<3053:EKWAUM>2.0. $\mathrm{CO}$;2. [Link]

Canziani, P. O., J. R. Holton, E. Fishbein, and L. Froidevaux, 1995: Equatorial Kelvin wave variability during 1992 and 1993. J. Geophys. Res., 100, 5193-5202, doi: 10.1029/94JD02330. [Link]

Cheng, C. Z. F., Y. H. Kuo, R. A. Anthes, and L. Wu, 2006: Satellite constellation monitors global and space weather. Eos, Trans., AGU, 87, 166, doi: 10.10 29/2006EO170003. [Link]

Dunkerton, T. J., 1997: The role of gravity waves in the quasi-biennial oscillation. J. Geophys. Res., 102, $26053-$ 26076, doi: 10.1029/96JD02999. [Link]

Ern, M., P. Preusse, M. Krebsbach, M. G. Mlynczak, and J. M. Russell III, 2008: Equatorial wave analysis from SABER and ECMWF temperatures. Atmos. Chem. Phys., 8, 845-869.

Fujiwara, M., K. Kita, and T. Ogawa, 1998: Stratospheretroposphere exchange of ozone associated with the equatorial Kelvin wave as observed with ozonesondes and rawinsondes. J. Geophys. Res., 103, 19173-19182, doi: 10.1029/98JD01419. [Link]

Fujiwara, M., F. Hasebe, M. Shiotani, N. Nishi, H. Vomel, and S. J. Oltmans, 2001: Water vapor control at the tropopause by equatorial Kelvin waves observed over the Galapagos. Geophys. Res. Lett., 28, 3143-3146, doi: 10.1029/2001GL013310. [Link]

Fujiwara, M., S.-P. Xie, M. Shiotani, H. Hashizume, F. Hasebe, H. Vomel, S. J. Oltmans, and T. Watanabe, 2003: Upper-tropospheric inversion and easterly jet in the tropics. J. Geophys. Res., 108, 4796, doi: 10.1029/ 2003JD003928. [Link]

Garcia, R. R. and M. L. Salby, 1987: Transient response to localized episodic heating in the tropics. Part II: Farfield behavior. J. Atmos. Sci., 44, 499-532, doi: 10.11 75/1520-0469(1987)044<0499:TRTLEH>2.0.CO;2. [Link]

Hajj, G. A., C. O. Ao, B. A. Iijima, D. Kuang, E. R. Kursinski, A. J. Mannucci, T. K. Meehan, L. J. Romans, M. de la Torre Juarez, and T. P. Yunck, 2004: CHAMP and SAC-C atmospheric occultation results and intercomparisons. J. Geophys. Res., 109, D06109, doi: 10.1029/2003JD003909. [Link]

Highwood, E. J. and B. J. Hoskins, 1998: The tropical tropopause. Q. J. R. Meteorol. Soc., 124, 1579-1604, doi: 10.1002/qj.49712454911. [Link] 
Hirota, I., 1979: Kelvin waves in the equatorial middle atmosphere observed by the Nimbus 5. SCR. J. Atmos. Sci., 36, 217-222, doi: 10.1175/1520-0469(1979)036 $<0217$ :KWITEM>2.0.CO;2. [Link]

Hitchman, M. H. and C. B. Leovy, 1988: Estimation of the Kelvin wave contribution to the semiannual oscillation. J. Atmos. Sci., 45, 1462-1475, doi: 10.1175/15200469(1988)045<1462:EOTKWC>2.0.CO;2. [Link]

Holton, J. R., 1972: Waves in the equatorial stratosphere generated by tropospheric heat sources. J. Atmos. Sci., 29, 368-375, doi: 10.1175/1520-0469(1972)029<0368 :WITESG >2.0.CO;2. [Link]

Holton, J. R. and R. S. Lindzen, 1972: An updated theory for the quasi-biennial cycle of the tropical stratosphere. J. Atmos. Sci., 29, 1076-1080, doi: 10.1175/1520-0469 (1972)029<1076:AUTFTQ>2.0.CO;2. [Link]

Holton, J. R., M. J. Alexander, and M. T. Boehm, 2001: Evidence for short vertical wavelength Kelvin waves in the Department of Energy-Atmospheric Radiation Measurement Nauru99 radiosonde data. J. Geophys. Res., 106, 20125-20129, doi: 10.1029/2001JD900108. [Link]

Melbourne, W. G., E. S. Davis, G. A. Hajj, K. R. Hardy, E. R. Kursinski, T. K. Meehan, and L. E. Young, 1994: The Application of Spaceborne GPS to Atmospheric Limb Sounding and Global Change Monitoring. National Aeronautics and Space Administration, Jet Propulsion Laboratory, California Institute of Technology, National Technical Information Service, Pasadena, California, USA.

Mote, P. W., T. J. Dunkerton, and D. Wu, 2002: Kelvin waves in stratospheric temperature observed by the Microwave Limb Sounder. J. Geophys. Res., 107, 4218, doi: 10.1029/2001JD001056. [Link]

Randel, W. J. and F. Wu, 2005: Kelvin wave variability near the equatorial tropopause observed in GPS radio occultation measurements. J. Geophys. Res., 110, D03102, doi: 10.1029/2004JD005006. [Link]

Randel, W. J., F. Wu, and W. R. Rios, 2003: Thermal variability of the tropical tropopause region derived from GPS/MET observations. J. Geophys. Res., 108, 4024, doi: 10.1029/2002JD002595. [Link]

Ratnam, M. V., T. Tsuda, T. Kozu, and S. Mori, 2006: Long-term behavior of the Kelvin waves revealed by CHAMP/GPS RO measurements and their effects on the tropopause structure. Ann. Geophys., 24, 13551366.

Rocken, C., Y. H. Kuo, W. S. Schreiner, D. Hunt, S. Sokolovskiy, and C. McCormick, 2000: COSMIC system description. Terr. Atmos. Ocean. Sci., 11, 21-52.

Salby, M. L. and R. R. Garcia, 1987: Transient response to localized episodic heating in the tropics. Part I: Excitation and short-time near-field behavior. J. Atmos. Sci., 44, 458-498, doi: 10.1175/1520-0469(1987)044<0458
:TRTLEH $>2.0 . \mathrm{CO} ; 2$. [Link]

Salby, M. L., D. L. Hartmann, P. L. Bailey, and J. C. Gille, 1984: Evidence for equatorial Kelvin modes in Nimbus-7 LIMS. J. Atmos. Sci., 41, 220-235, doi: 10.11 75/1520-0469(1984)041<0220:EFEKMI>2.0.CO;2. [Link]

Salby, M. L., P. Calalghan, S. Solomon, and R. R. Garcia, 1990: Chemical fluctuations associated with vertically propagating equatorial Kelvin waves. J. Geophys. Res., 95, 20491-20505, doi: 10.1029/JD095iD12p204 91. [Link]

Seidel, D. J., R. J. Ross, J. K. Angell, and G. C. Reid, 2001: Climatological characteristics of the tropical tropopause as revealed by radiosondes. J. Geophys. Res., 106, 7857-7878, doi: 10.1029/2000JD900837. [Link]

Shiotani, M. and T. Horinouchi, 1993: Kelvin wave activity and the quasi-biennial oscillation in the equatorial lower stratosphere. J. Meteorol. Soc. Jpn., 71, 175-182.

Shiotani, M., J. G. Gille, and A. E. Roche, 1997: Kelvin waves in the equatorial lower stratosphere as revealed by cryogenic limb array etalon spectrometer temperature data. J. Geophys. Res., 102, 26131-26140, doi: 10.1029/96JD04012. [Link]

Smith, A. K., P. Preusse, and J. Oberheide, 2002: Middle atmosphere Kelvin waves observed in Cryogenic infrared Spectrometers and Telescopes for the Atmosphere (CRISTA) 1 and 2 temperature and trace species. $J$. Geophys.Res., 107, 8177, doi: 10.1029/2001JD000577. [Link]

Sridharan S., T. Tsuda, T. Nakamura, T. Kozu, S. Mori, and J. M. Russell, 2006: Observations of the 7-day Kelvin Wave in the Tropical Atmosphere During the CPEA Campaign. J. Meteorol. Soc. Jpn., 84A, 259-275, doi: 10.2151/jmsj.84A.259. [Link]

Tindall, J. C., J. Thuburn, and E. J. Highwood, 2006a: Equatorial waves in the lower stratosphere. I: A novel detection method. Q. J. R. Meteorol. Soc., 132, 177-194, doi: 10.1256/qj.04.152. [Link]

Tindall, J. C., J. Thuburn, and E. J. Highwood, 2006b: Equatorial waves in the lower stratosphere. II: Annual and interannual variability. Q. J. R. Meteorol. Soc., 132, 195-212, doi: 10.1256/qj.04.153. [Link]

Tsai, H. F., T. Tsuda, G. A. Hajj, J. Wickert, and Y. Aoyama, 2004: Equatorial Kelvin waves observed with GPS occultation measurements (CHAMP and SACC). J. Meteorol. Soc. Jpn., 82, 397-406, doi: 10.2151/ jmsj.2004.397. [Link]

Tsuda, T., Y. Murayama, H. Wiryosumarto, S. W. B. Harijono, and S. Kato, 1994: Radiosonde observations of equatorial atmosphere dynamics over Indonesia 1. Equatorial waves and diurnal tides. J. Geophys. Res., 99, 10491-10505, doi: 10.1029/94JD00355. [Link]

Tsuda, T., M. Nishida, C. Rocken, and R. H. Ware, 2000: A global morphology of gravity wave activity in the 
stratosphere revealed by the GPS occultation data (GPS/MET). J. Geophys. Res., 105, 7257-7273, doi: 10.1029/1999JD901005. [Link]

Wallace, J. M. and V. E. Kousky, 1968: Observational evidence of Kelvin waves in the tropical stratosphere. $J$. Atmos. Sci., 25, 900-907, doi: 10.1175/1520-0469(196 8)025<0900:OEOKWI>2.0.CO;2. [Link]

Wheeler, M. and G. N. Kiladis, 1999: Convectively coupled equatorial waves: Analysis of clouds and temperature in the wavenumber-frequency domain. J. Atmos. Sci., 56, 374-399, doi: 10.1175/1520-0469(1999)056<0374 :CCEWAO > 2.0.CO;2. [Link]

Wickert, J., C. Reigber, G. Beyerle, R. Konig, C. Marquardt, T. Schmidt, L. Grunwaldt, R. Galas, T. K. Meehan, W. G. Melbourne, and K. Hocke, 2001: Atmosphere sounding by GPS radio occultation: First results from CHAMP. Geophys. Res. Lett., 28, 3263-3266, doi: 10.1029/2001GL013117. [Link] 